\title{
On the Concept of Recognition in Media Art: Emotional reactions, empathetic interactions
}

\author{
Aleksandra Kaminska \\ Department of Communication, Université \\ de Montréal \\ Canada \\ a.kaminska@umontreal.ca
}

\begin{abstract}
Biometric technologies have transformed recognition into an empirical and automated activity. But recognition is not just a matter of identification or surveillance. As computer systems become capable of detecting human emotion, we are reminded of philosophical approaches to recognition that place it as central activity of human self-realization and social existence. Bringing together these dual notions of recognition, this paper considers how artists are taking hold of the technical possibilities of recognition to make political the media artwork. Specifically, it turns to Karen Palmer's interactive film RIOT (protoype) (2016), in which the narrative depends on the recognition of the participant's emotive facial expressions, and Erin Gee's Project H.E.A.R.T. (2017), a virtual reality artwork in which the participant's "enthusiasm" is harnessed via a biosensor. Through these examples, the paper proposes a way to think the politics of media art by pivoting on the technologies, practices and philosophies of recognition.
\end{abstract}

Recognition. Biometrics. Human-computer interaction. Affective computing. Politics of media art. Erin Gee. Karen Palmer.

\section{INTRODUCTION}

The automated recognition of human emotions by computers relies on biometric analysis of the body, but it is often considered as slightly apart from technologies of biometric recognition and their emphasis on identification. When defined in its narrow technical sense, biometrics refers to the ability of computer systems to identify digital representations of a person's unique physiological features (van der Ploeg 1999), and this does not include the mutations produced through emotion. Writing specifically about technologies that recognize facial features, Kelly Gates (2011) explains this distinction by noting that biometric facial recognition and automated facial expression analysis "pose distinct problems, and they represent related but somewhat distinct research and development efforts" (p.8). However, she also argues that analysing these domains separately has its limitations, particularly when searching for an understanding of the changing relationships between humans and computers: "the differentiation of the face along these lines serves the purposes of scientific investigation and technical engineering more than it does a theoretically rich understanding of human communication" (ibid.). One obvious commonality between these research areas is their compression of humans into numbers and categories, whether working on the body as a "fixed" indexical surface of human identity, or when evaluating individual dispositions by turning to the body's ephemeral and affective performances and displays of emotion. This paper adopts this unified perspective to think conceptually about computers that can read, recognize and respond to bodies, and specifically pauses on the concept of recognition itself as one that may offer a way of thinking across a variety of technologies whose aim is to better "see" and communicate with humans. While implicitly this conversation belongs within work on humancomputer interaction, affective and human-centred computing, this paper is interested in media art as a specific context for the practice of recognition technologies and philosophies.

From the perspective of communication and media studies, recognition-whether of bodies or emotions-can be understood as a communicative and mediated activity between agents in which there are specific technical processes of reading, decoding, matching, response, etc. ${ }^{1}$ As these have become increasingly empirical and automated, recognition has accordingly transformed into an activity conceived as an objective technical 
application. However, as an idea that has preoccupied philosophers for centuries, recognition is far from having a self-evident meaning. By turning towards this more intricate study of recognition as a human and social activity, we can work across the distinctions between identification and individuation that emerge from the technical difference between identifying bodies and assessing individual conditions and states. To do so, this paper considers two recent works that use technologies of emotional recognition to examine how artists are taking hold of the technical possibilities of recognition to produce experiences that make political the media artwork. The aim is to offer a way into a political philosophy of media art, one that pivots around the technologies, the practices and the meanings of recognition, or what could also be described as the science, art and philosophy of recognition.

\section{RIOT \& THE MEANINGS OF RECOGNITION}

Specialists in fields such as computer science and psychology have been united in their effort to develop automated digital systems that can measure and determine emotions. There are a number of assumptions made in this work: that emotions are quantifiable and measureable machine-readable states; that humans may lose their ability to hide their true feelings; and that the future of relationships between humans and the machine-world relies in part on this ability for computers to recognize and respond to individual human emotion. Here emotions become normalized and folded into the repressive structures of the surveillance and neoliberal apparatus (Gates 2011).

Riot (Prototype) (2016) by the British filmmaker Karen Palmer is "an emotionally responsive, liveaction film, with immersive 3D sound design, which uses facial recognition and $\mathrm{Al}$ technology to navigate through a dangerous riot" (Palmer n.d.). The participant stands on a platform facing a television screen, above which a surveillance camera monitors her facial features. The action on the screen takes place in the desolate exterior of a complex of concrete buildings, staircases and passageways. The participant soon realizes she is the protagonist and victim, and is being chased by police officers. The point-of-view changes in the moments when the narrative requires direction and the camera takes a facial scan of the participant. In these moments she sees the scene as if through her own eyes, giving the impression of a face-to-face confrontation with the police authority/camera scanning her face.

The sequence of events in the film varies based on the facial reactions and discernible emotions of the participant. In this sense, the face "runs" the program and thus serves as the navigating device that determines the storyline: "Respond with fear and the film goes in one direction... respond with aggression it goes in another" (Palmer n.d.). Placed in the context of an exhibition on immersion, ${ }^{2}$ this "responsive film" was one of the only works that was not predicated on entering a VR environment with the use of goggles, but rather offered a look into a future where immersive and interactive experiences are augmented through a customized responsive experience that uses technologies of recognition.

Despite this context, the potentially personalized responsiveness of the system that recognizes presents particular technical, practical and political configurations that cannot be contained in the more general terms of interaction, participation or immersion. Technologies such as those of facial or voice recognition use the body's biometric signature as a code for machines to read persons, thereby entering human bodies into a world of computer processing and digital information networks. To date, most of the applications developed for technologies of recognition are fuelled by logics of optimized efficiency and productivity, with many ultimately developed to complement or altogether replace the work and labour of humans and the socalled weakness of our interpretative and fallible "human" judgement. As the thinking goes, why have a person examine faces on a security monitor when the computer programmes of machinic vision can do so much more quickly and reliably. Like with many other activities today, recognition has fallen under the scope of things-that-we-trust-computers-can-dobetter-than-us, with trust being the operative word. Indeed, humans must trust computers to "allow" them to make humans so vulnerable, transparent and knowable. As Craig Robertson notes in his work on passports and identification, there is a "perceived need to lessen the role of individuals in the verification of identity" (2010, p. 17), and biometric technologies are an example of how computers have been entrusted to recognize in our stead.

It could be said that technologies of recognition have inserted themselves into media art practices in paradoxical ways. On the one hand, they are used to improve the interactive experience following the same reasoning as (or an example of) the work done in $\mathrm{HCl}$. On the other, however, technologies of recognition are also the subject of criticism, particularly in regard to the way they are used to "improve" security and surveillance (as for example in Rafael Lozano-Hemmer and Krzysztof Wodiczko's Zoom Pavilion from 2015). In this in between of use and critique, strategy and tactic, artists perform once again their role as intermediaries and negotiators of the applications, protocols and functionalities of emerging technologies. They do so proposing a model not that categorically rejects and refuses, but that rethinks and reimagines, for example by making human- 
computer interactions not more efficient, but more intimate or caring. Moreover, the integration of technological recognition as part of an artistic environment and experience has created new conditions and settings of recognizability, which are reminders of the manifold meanings of this term and the breadth of its activity, not merely as technical process in which humans are identified or verified, but as a central concept for thinking about the ways people form identities and exist in a society in relation to others.

As technical process, recognition has become a word entangled with $\mathrm{Al}$, machine learning, robotics and the work of creating more "human" ("natural" or seamless) connections between humans and computers through the machine-readability of our biometric data. Recognition here is a process of unidirectional reading in which individuals are processed automatically and algorithmically through the surface of their material bodies. In this situation, the moment of recognition occurs when "a matching template is found, the person presenting themselves is 'recognized' and counts as 'known' to the system" (van der Ploeg 1999, p. 37). ${ }^{3}$

Stepping away from the technical universe however, recognition takes on a much vaster scope. The philosopher Charles Taylor (1992) has for example noted that recognition is a "vital human need" (p. 26), one that taps into a deep human desire to be to be seen, heard, known, understood and accepted by others. It is part of the long history of thinking about the construction of identity, specifically as defined by a relation between the recognized and the recognizer. The most famous undertaking of the term is by Hegel, namely in Phenomenology of Spirit, where he argues that construction of autonomy, self-consciousness, self-realization and the "I" happen only through a process of recognition by the other that allows us to "cognize oneself" (Margalit 2001, p. 128). It is only through the other that the self comes into being, and only through mutual recognition that the self as social being comes into existence. Taken up in John Durham Peters' influential work on the concept of communication, Hegel becomes a kind of vanguard theorist of communication for whom communication is a "political and historical problem of establishing conditions under which the mutual recognition of self-conscious individuals is possible" (Peters 2000, p. 112). For Hegel, communication is a process of mutual recognition that is needed to "establish a vibrant set of social relations in which common worlds can be made" (Peters 2000, p. 118). As in a reciprocal mechanism there is a process reliant on feedback: one's sense of identity is based on the response received from others; in other words, I can only be made legible to myself if you read me correctly. This idea of the self as emerging and mutually constituted through another underlies the relational aspect of recognition, but also plants the seeds for Foucauldian imbalances of power as the observed and the observer become unequally recognizable to one another. These simultaneous and entwined individual and social aspects of recognition make it a crucial political term for thinking about the co-existence of pluralities in democratic societies. Indeed, recognition has become and remains particularly relevant in the discourse on human rights and equality whether in their theoretical examination or in the activist and political work on the rightful recognition of marginalized persons and communities. ${ }^{4}$

For Hegel, recognition makes possible a common world because it is the moment in which the self comes into existence through the other. For intellectual traditions that rather defend the idea that there is such a thing as an independent private self, the desire for recognition goes hand in hand with a human longing to be taken and valued by another for all of our messy complexity, our illogical eccentricities, the baggage that we carry, the stories we can tell-in short, for our unquantifiable interior self. It is a desire to be recognized for all of the things that make us who we are but that are impossible to reduce or flatten to data; that are elusive, mutable and perhaps even unique; that constitute our multilayered identity beyond the measurable surface or standardization of the body. This is all to say that while in political philosophy recognition is a rich and diverse concept that engages with a cross-section of debates and a "family or problems" (Margalit 2001, p. 127), including the very nature of the self, it is largely in contrast with, and overshadowed by, the ways the term is circulated in technical contexts.

Such seemingly divergent notions of recognition are not however recent constructions solely based on new technological possibilities. Rather, they are part of the constellation of meanings that make up the notion of recognition, which can be separated into three general categories (Margalit 2001) ${ }^{5}$ :

1. The first major meaning of recognition is as identification, in the sense that a person can (re)identify and recognize someone they have seen before. This notion fits into a technical understanding of recognition, or as a way that a set of features or data can be read and matched to some previous knowledge or database. A concern with bodies and biometrics, whether human or machine readable, belongs in this category;

2. The second set of meanings concerns social and political recognition in the form of acknowledgement and respect. This is the sense of recognizing someone's status, achievements or rights. Here recognition is necessarily a positive affirmation of someone's identity that takes shape in a 
process of feedback. This is the realm of politics and philosophy.

3. Finally, there is the cognitive sense, or the moment of realisation of a mistake (for example, to recognize we misjudged a situation).

Technologies of recognition can operate across all three categories of meaning. A work like Riot is conceptually interesting precisely because recognition performs (at least) two meanings at once, something that is possible through the setting in which the action takes place, as well as the narrative and technical emphasis on the recognizability of emotion. The participant guides the action through identifiable machine-readable emotional expression, while the narrative of the work involves a confrontation with a police officer providing "security," a situation that suggests a reflection on the performance of the right emotions in order to be "rightfully" treated and acknowledged. Recognizable emotion is the means towards interaction with the artwork and its computer system, with the participant expecting an accurate reading by the camera and the appropriate feedback.

Writing about David Rokeby's classic Very Nervous System, Jean Gagnon (2016) describes the way a work becomes a device that is performed, a digital instrument that is played by the participant. He elaborates:

Through the use of this device-which can be described as a 'instrument'-the body also becomes a mediator in this space-time. The body and gestures stimulate the instrument, and in return, the audio feedback is immediate. The instrument reacts to the slightest movement of a finger or the blink of an eye (p. 493-494).

The point Gagnon is making about the body as that which plays the instrument that is the artwork becomes all the more relevant when this body can be recognized not merely as "a body" that gestures and moves, but increasingly as a body in a specific state. The face is important in both Gagnon's analysis of Rokeby's work and in Palmer's Riot, though the difference between the two perhaps speaks precisely to the shift from interaction to the more specific aspects made possible by technologies of recognition. For instance, Gagnon describes the face in Very Nervous System as a "surface for play and control" (p. 496) but he wonders at the capacity of this face to express sentiments or feelings. He notes, "the playing surface is clearly the performer's face, and the micro-movement of the facial features reflect the pleasure of playing" (ibid.) so that the face plays the instrument, but it is not a face that is connected to an identity or a state other than the one of being "at play."
Once in the territory of emotional recognition, however, the relationality between "agents" is precisely affected by the responsiveness of the machine system to what has been empirically established as a particular state. And it is one of the questions Palmer works through in Riot. She notes:

I'm trying to show you that you're the creator of your own reality... RIOT measures calm, anger, and fear. So you come into contact with a riot cop in there, and if you're angry, it has a different narrative path than if you're fearful or calm. It kind of shows you, 'I can override this operating system in a way, I can be calm and elicit the response I want.' It reveals a lot about yourself...." (Phi Centre 2017).

In this mechanism of recognition, the work makes participants aware of how others perceive them, which becomes important not only for the making of their own (sense of) self and the understanding that comes from seeing another's point of view, but also, ultimately, for a working towards an ability to relate and empathize.

\section{PROJECT H.E.A.R.T. \& THE UNCERTAINTY OF RECOGNITION}

The matter of empathy is raised in Canadian artist Erin Gee's Project H.E.A.R.T. (2017), H.E.A.R.T standing for Holographic Empathy Attack Robotics Team. This VR game "interrogate[s] the emotional toll of real war" (New World Notes 2018) by connecting a player's emotional body to action in digital space. The work is a play on popular militarystyle shooter video games, but here the avatar's work is to motivate soldiers who become depressed after they kill the enemy. Through a biosensing system that responds to the player's measurable "enthusiasm," it is the player's physiological response that becomes responsible for encouraging soldiers to keep fighting and that does the work of what the artist calls "combat therapy." More specifically:

Through principles of emotional physiology and affective computing, the device gathers data relative to heart rate and blood flow from index finger, and skin conductance from middle and ring fingers of users. The biodata is read by a microcontroller and transferred to Unity VR, thus facilitating emotional interactivity: a user's enthusiasm (spikes in signal amplitude in skin conductance, elevated heart rate, and shifts in amplitude of the pulse signal) stimulates the holographic pop star to sing in the virtual warzone, thus inspiring military fighters to continue the war, and create more enemy casualties (Gee 2017). 
This description explains that the work harnesses emotion to create an experience "with heart," one that envelops the military situation with a cloak of empathy as the player becomes the one responsible for death, not through his or her playing skills, but through the less controllable controller that is their body's reaction, implicating them in a way that might make them feel guilty for the actions performed due to their rising palpitations. Here the participant is not so much the victim (as in Riot) as a self-conscious perpetrator. That accelerated heartbeat is equated in this scenario with an endorsement of fighting rather than, for example, an expression of fear or panic, is a reminder that data still require human interpretation and can be manipulated to say things about us that we may not agree with. While there might be an assumption that our body "gives us away" as we struggle to conceal emotion, in this case the betrayal does not lead to a revelation of the truth but rather to its distortion as physiological reactions are misread and/or misappropriated. Just as in other forms of traces human's leave behind, they are open to debate and to speculation. ${ }^{6}$ This makes Project H.E.A.R.T. not just a display of the ways recognition technologies allow the participant to control and be in charge of the work, but a study in how this control is turned back onto the participant and used to produce in her a reaction. Indeed, it is not obvious for players in Project H.E.A.R.T. whether they "win" the game if they are enthusiastic, with the unusual scenario disrupting the clarity for players about which side they are on and how to achieve or determine success. The recognition that takes place is of the player's own indeterminate position, where winning becomes not a technical question but a political (and ethical) one. In both Project H.E.A.R.T. and Riot, technologies of recognition are explicitly used to help the participant realise something about themselves as individuals and social beings, more even perhaps than about the technologies being used, producing a moment of recognition in the cognitive sense, a realization that something is not quite as it seems.

Riot and Project H.E.A.R.T. are both interactive experiences. But technological recognition is not necessarily reciprocal, active or interactive. As surveillance applications demonstrate, one can recognize another in the sense of identifying them, while the one who is recognized might be unware of this attention. Recognition is a strange concept then, containing at once the idea of validation and of monitoring. In this the mutation of recognition becomes apparent, from a philosophy based on a mutual affirmation, to a device and mechanism of control, whereby its technologies become a materialization of the power of those who can authoritatively read and match, identify and acknowledge.

\section{SPACES OF RECOGNITION}

Hannah Arendt's notion of appearance becomes particularly useful when recognition is understood as a moment of affirmative visibility. She writes:

Nothing could appear, the word
"appearance" would make no sense, if
recipients of appearances did not exist-
living creatures able to acknowledge,
recognize, and react to-in flight or desire,
approval or disapproval, blame or
praise- what is not merely there but
appears to them and is meant for their
perception. In this world which we enter,
appearing from a nowhere, and from which
we disappear into a nowhere, Being and
Appearing coincide... Nothing and nobody
exists in this world whose very being does
not presuppose a spectator. In other words,
nothing that is, insofar as it appears, exists
in the singular... Plurality is the law of the
earth (Arendt 1977, p. 19).

Arendt's thought places recognition within the potentiality of a space of appearance that has, in the age of ubiquitous surveillance, tipped over into its opposite, as a space marked by one's inability to hide and to remain private, unseen and anonymous. What becomes then of the power of the gaze of the other? Is it, like Arendt argues, that the gaze "celebrates the visibility of the public world," or is the gaze as Foucault would have it, "relentlessly negative" (Marquez 2012, p. 9). The ways that recognition is defined and practiced creates a kind of see-saw in this search for balance between social space as Arendtian space of appearance and a Foucauldian space of surveillance.

The political philosopher Xavier Marquez compares these accounts and writes: "These two types of spaces represent poles in a spectrum of possibilities for which the settings where selves and subjects are partially constituted by the ways in which they become visible" (2012, p. 7). This duality defines the paradox at the heart of recognition, one that has only been amplified by new technologies that allow for seemingly personally attuned forms of inter-action and communication, while also playing into the hands of a computerized surveillance apparatus that precisely turns this vulnerable human desire for recognition against us. As recognition is both empowering and constraining, it becomes both what is needed in a democracy and what impedes the liberties it should provide. The fluidity of identity that exists in the space of appearance becomes crystallized in the quantified and increasingly machine-readable space of surveillance, and recognition becomes the instrument not through which we mutually construct, but through which we control each other (see Marquez 2012). 
This model of duelling spaces could be mapped onto the aforementioned definitions of recognition: the space of appearance corresponds to the social and political notion of recognition as a moment of validation, respect and acknowledgement of persons; in the space of surveillance recognition takes on its meanings as the identification and verification of bodies.

\section{CONCLUSION}

It may at first appear that the philosophical baggage that comes along with the word recognition is an unnecessary diversion, somehow separate from the biometric readings that computer systems perform when they assess human bodies, but these layered meanings of recognition are helpful for considering the evolving relations between humans and machine systems. While humans might seek responsive computers that can react to emotions and persons, recognition is also what computers seek from humans as they prove that they can be trusted to read and respond to humans accurately.

This exploratory paper clearly raises more questions than it can answer, which can be summarized as follows. First, what can media artists tell us about the realities and possibilities of technologies of recognition? Second, how does the concept of recognition help think the bringing together of, and perhaps even the dissolution between, human and machine? And finally, could the computer, through its attentiveness to human emotion, do the political and social work of recognition? The boom in biometrics and the accompanying transformation of recognition into an empirical process is an opportune moment to consider anew what the action of recognition is or does. Doing so might provide a theoretical avenue to help bring politics into our thinking on human-computer communication and its varied expressions in media artworks.

\section{REFERENCES}

Arendt, H. (1977) The Life of the Mind. Harcourt, New York.

Durham Peters, J. (2000) Speaking into the Air: A History of the Idea of Communication. University of Chicago Press, Chicago.

Gagnon, J. (2016) Viewer-Instrumented Play: Very Nervous System. In Bianchini, S. \& Verhagen, E. (eds.). Practicable, The MIT Press, Cambridge.

Gates, K. A. (2011) Our Biometric Future: Facial Recognition Technology and the Culture of Surveillance. New York University Press, New York.
Gee, E. (2017) Project H.E.A.R.T. Personal website: http://eringee.net/project-h-e-a-r-t// (retrieved 1 May 2018).

Margalit, A. (2001) Recognizing the Brother and the Other. Proceedings of the Aristotelian Society: Supplementary Volumes, 75, pp.127-139.

Marquez, X. (2012) Spaces of Appearance and Spaces of Surveillance. Polity 44(1), pp. 6-31.

New World Notes blog. (2018) Project H.E.A.R.T: A Virtual Reality War Game Where Soldier Morale is Controlled by the Player's Real Emotions.

http://nwn.blogs.com/nwn/2018/03/vr-gameempathy-joy-project-heart-erin-gee.html (retrieved 1 May 2018).

Palmer, K. (n.d.) Riot. Personal website: http://karenpalmer.uk/portfolio/riot/ (retrieved 1 May 2018).

Phi Centre website. (2017) How do you Deal with Fear? http://phi-centre.com/en/post/en-lucidrealities-karen-palmer-riot/(retrieved 1 May 2018).

Robertson, C. (2010). The Passport in America: The History of a Document. Oxford University Press, New York.

Taylor, C. (1992). The Politics of Recognition. In Gutmann, A. (ed.). Multiculturalism: Examining the Politics of Recognition, Princeton University Press, Princeton.

Van der Ploeg, I. (1999). Written on the Body: Biometrics and Identity. SIGCAS Computers and Society 29(1), pp. 37-44.

\section{NOTES}

1. Other disciplines might focus on different concepts. For example, art history might seek to place technologies of recognition as an extension of participatory art, while film studies might think about its effects on narrative structures.

2. It was presented as part of the Lucid Realities exhibition at the Phi Centre in Montreal in 2017, as part of a showcase of immersive works under the name of Sensory Stories, organized in collaboration with the Future of StoryTelling (FoST) organization.

3. What is notable in this definition is the qualified use of recognition and knowledge-both are placed in quotation marks-which might indicate that these actions are, or at least were at the time Ploeg is writing in 1999, considered a bit too human for a computer to perform. 
4. See for example Judith Butler's recent work Notes Towards a Performative Theory of Assembly. Harvard University Press, Cambridge (2015)

5. Drawing on Michael Inwood's entry Recognition in A Hegel Dictionary. Blackwell, Oxford (1992).

6. Which does raise the question of what might happen if emotional responses are linked to identification databases. 